\title{
BIOCOMPOSITE CHARACTERIZATION OF BAGASSE STARCH DERIVED FROM CASSAVA REINFORCED BY ACETYLATED BAMBOO CELLULOSE AND PLASTICIZED BY EPOXIDIZED WASTE COOKING OIL
}

\author{
S. Silviana ${ }^{1, *}$ and A. Subagio ${ }^{2}$ \\ ${ }^{1}$ Department of Chemical Engineering, Diponegoro University, 50275, Indonesia \\ ${ }^{2}$ Department of Physics, Diponegoro University, 50275, Indonesia \\ *E-mail: silviana@che.undip.ac.id
}

\begin{abstract}
Reinforcing starch-based biocomposites have been investigated by many agents. This paper observes the characterization of cassava solid waste/bagasse starch (BS) reinforced bamboo cellulose micro fiber (MFC) and epoxidized waste cooking oil (EWCO). Previous research prepared EWCO through acetic acid-hydrogen peroxide process. The EWCO and glycerol were used as a plasticizer and the lime juice as the crosslinker. The products have been characterized tensile strength by texture analyzer, qualitative structural by FTIR, thermal by differential scanning calorimetric, and crystalline structure by spectra of XRD. The highest tensile strength of $25.8 \mathrm{MPa}$ was achieved at the composition of MFC $1 \%$-w/w, glycerol of $0.25 \%-\mathrm{v} / \mathrm{v}$, lime juice of $0.125 \%$-v/v, and EWCO of $0.125 \%$-v/v. The products confirmed the disappearance of the acetyl moiety at $1732 \mathrm{~cm}-1$ by FTIR, the diffraction peak at $15^{\circ}, 17^{\circ}$, and $23^{\circ}$ for neat BS, while the peaks disappeared at a range of $15^{\circ}-23^{\circ}$ for acetylated BS. The peak at $16.5^{\circ}$ and $22.5^{\circ}$ for cellulose I of neat and acetylated MFC. The weight loss and degradation temperature during thermal analysis were achieved about $22 \%$ and $290{ }^{\circ} \mathrm{C}$, respectively. Glass transition temperature of products revealed decrease excluding the mixed of acetylated $\mathrm{MFC}$, neat BS, and acetylated BS with an increase up to 117 ${ }^{\circ} \mathrm{C}$.

Keywords: Bamboo, Biocomposite, Cassava Bagasse Starch, Epoxidized Waste Cooking Oil, Microfibrillated Cellulose
\end{abstract}

(C) RASĀYAN. All rights reserved

\section{INTRODUCTION}

Bio-based composites can be generated by preparing a matrix of carbohydrates or proteins, which are extracted either from plant or animal sources ${ }^{1}$. One of the most attractive biocomposite materials is by utilizing starch due to its high availability, inexpensive, and renewable material to produce bio-based polymer such as bio-plastic. Other natural sources can be used as matrices such as the protein of sunflower ${ }^{2}$, Amaranth flour ${ }^{3}$, Pea $\operatorname{starch}^{4}$, rice flour and polybutylene adipate co-terephthalate ${ }^{5}$, cornflour and chitosan ${ }^{6}$. Many efforts have been investigated to overcome drawback of starch-based bio-composite from cassava bagasse and cassava starch by blending with polylactic acids ${ }^{7}$, and reinforced by several kinds of material such as date palm and flax fiber ${ }^{8}$, clay nanoparticles ${ }^{9}$, thermoplastic chitosan $^{6}$, polyaniline $/ \mathrm{Fe}_{3} \mathrm{O}_{4}{ }^{10}$, gelatine ${ }^{11}$, bamboo nanofibrils ${ }^{12}$, cellulose micro fibrillated of carrots ${ }^{13}$, micro fibrillated cellulose (MFC) of bamboo ${ }^{14}$. MFC commercially can be prepared from sequence of chemicals treatments such as delignification and bleaching ${ }^{15}$. Another preparation method can be executed by mechanically such as micro fluidizing, high pressure grinding, high-pressure homogenizer ${ }^{16}$. Another source as matrix is referred to as cassava bagasse starch. Cassava bagasse as solid waste is released from more than $75 \%$ of the raw material of cassava starch production and still consists of starch more than 30$40 \%$. Furthermore, the bagasse starch (BS) potentially affects the environment as huge organic waste ${ }^{17}$. Therefore, cassava solid waste (bagasse starch) utilization as a bio-composite matrix can reduce this effect on the environment. Use of crosslinker and plasticizer are also common additives in bio-composite

Rasayan J. Chem., 12(3), 1470-1477(2019)

http://dx.doi.org/10.31788/RJC.2019.1235240

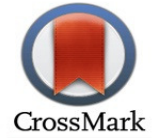


preparation. In this research, the bio-crosslinker used was citric acid from lime, the bio-plasticizer prepared from epoxidized waste cooking oil (EWCO) and glycerol, while the used matrix referred to cassava solid waste starch and reinforcing agent of fiber from bamboo MFC. However, this matrix and reinforcement have drawbacks regard with their properties. Previous research had been conducted modified cassava solid waste (bagasse starch) with bamboo MFC by using an acid such as ethanoic acid or glacial acetic acid (GAA) to enhance physical performance ${ }^{18}$. Bamboo fiber has been already reinforced many kinds of composite with good results, such as for polyvinylchloride (PVC) ${ }^{19}$, starchpolyvinyl acetates (PVA) $)^{12}$, polylactic acids (PLA) ${ }^{7}$, and composite derived from sago $\operatorname{starch}^{14}$. Bamboo cellulose fiber as one of the natural fibers have been used in biocomposites preparation ${ }^{20}$. Additional of lime juice as bio-crosslinker in sago starch-based bio-composite reinforced chicken feather keratin can increase mechanical properties ${ }^{21}$. The crosslinker, citric acid of lime, is aimed to enhance tensile strength $^{22}$, while the plasticizer, water content of lime juice, is proposed to increase flexibility ${ }^{23}$. Commonly, citric acid can be used as a good crosslinker for biocomposite ${ }^{24}$. The EWCO utilization as bio-plasticizer could improve to increase tensile strength and thermostability of sago starch-based biocomposite reinforced MFC of bamboo ${ }^{25}$. Moreover, EWCO was reported that it generated higher impermeable to oxygen for composite regarding be potential packaging of oxygen-sensitive food than that of epoxidized soybean oil ${ }^{26}$. Based on other plasticizer drawbacks, bio-plasticizer from vegetable oil have been investigated such as soybean oil, rubber seed oil, corn oil, neem oil due to lower toxicity, renewable, biodegradable, and low $\operatorname{cost}^{26}$. The objective of the paper is to utilize cassava bagasse as a matrix of composite reinforced by acetylated MFC of bamboo, plasticized by EWCO, and crosslinked with lime with further characterization of the biocomposite. Characterization of the product have been carried out in several kinds of analysis, i.e. mechanical by tensile strength, thermal stability by DSC-TGA analysis, qualitative functional group structural by FTIR analysis, and crystallinity by XRD analysis.

\section{EXPERIMENTAL}

Glacial acetic acid, potassium hydroxide pro analysis 99\%, phenolphthalein, HNO3 (65\%), Wijs solution, cyclohexane (for analysis), and sodium hydroxide were purchased from Merck supplier (100\%). Other chemicals such as hydrochloric acid with $37 \%$, toluene $99.5 \%$, sulfuric acid (technical grade), and diethyl ether (analysis grade) used the product of Mallinckrodt Chemicals-USA, hydrogen peroxide $\left(\mathrm{H}_{2} \mathrm{O}_{2}\right)$ with technical grade used was manufactured by Evonik Industries in Indonesia. Ethanol with technical grade was purchased from the local acid manufacturer (PT. Indo Acidatama) in Indonesia. Sodium thiosulfate pro analysis was supplied by Sigma Aldrich. All chemicals were directly used without any purification. Cassava (Manihot esculenta) solid waste (bagasse) was supplied from the home industry in PatiIndonesia. Bamboo stem (Dendrocalamus asper) was purchased from Sragen-Indonesia. Lime (Citrus aurantifolia) was bought at a traditional market in Semarang. Used cooking oil from commercial palm oil was collected from the small food industry of Semarang and first separated from solid waste.

Isolation of MFC from bamboo stem through chemical treatment and EWCO preparation have been performed based on previous research ${ }^{25}$. The acetylation procedures for the MFC of bamboo and the cassava bagasse starch referred to previous research ${ }^{18}$. Epoxidation of waste cooking oil method was carried out by use of previous without any modification ${ }^{25,27}$. Starch-based biocomposite preparation referred to previous research ${ }^{14}$. The further procedure, it was accomplished preliminary research to achieve a range of concentration of EWCO, glycerol, lime juice, and MFC of bamboo. Moreover, it was observed the composition between neat and acetylated material. Afterward, the conditions range were implemented on the variable of lime juice, MFC, glycerol, and EWCO concentrations upon the good result of tensile strength. The optimum tensile of samples were then characterized with instrument analysis of FTIR, XRD, and DSC-TGA to observe the performance of biocomposite. In the beginning, cassava BS have been analyzed to ensure the feasibility of cassava BS as potential matrix source. The results are shown in Table- $1^{28}$.

The isolation of MFC was executed with a sequence of chemical treatment such as extraction by using Soxhlet apparatus, delignification and bleaching by beaker glass of $2000 \mathrm{ml}$, vacuum filter, oven, and 
high energy milling (HEM). The acetylation reaction existed in beaker glass equipped hot stirrer and $\mathrm{pH}$ meter. The epoxidation was executed in a laboratory scale with a capacity of $500 \mathrm{ml}$ magnetically stirred flask which immersed in an oil bath. The thermocouple was used to control the temperature. MFC with distillate water must be homogenized at a certain concentration by ultrasonic homogenizer (the power of 150 watts and the frequency of $20 \mathrm{kHz}$ ) for $4 \mathrm{~h}$. Composite was prepared by mixing of MFC solution with 4 wt.\% of BS in a beaker glass on the hot stirrer at a temperature of gelatinizing. After mixing with plasticizer and crosslinker, the solution was poured onto acrylic casting and followed by drying at room temperature.

Table-1: Content Analysis of Isolated Starch from Cassava Solid Waste (Bagasse) ${ }^{28}$

\begin{tabular}{c|c|c|c}
\hline Component & Starch content $(\%)$ & Amylose content $(\%)$ & Amylopectin content $(\%)$ \\
\hline Commercial starch & 42.75 & 16.70 & 30.67 \\
\hline Isolated cassava BS & 79.11 & 12.09 & 62.41 \\
\hline
\end{tabular}

\section{RESULTS AND DISCUSSION}

Tensile strength (TS) of the samples was determined using CT3 Texture Analyzer (AMETEK Brookfield, USA). Three repetitions were carried out per sample of the composite using rectangular strips ( $5 \mathrm{~mm}$ x 20 $\mathrm{mm}$ ). This research was observed with the effect of matric and reinforcement composition, kind of plasticizers, and crosslinker of lime juice.

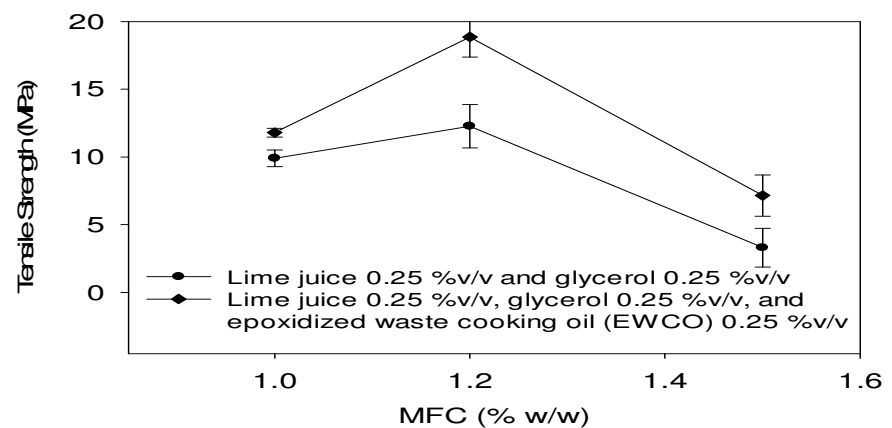

(a)

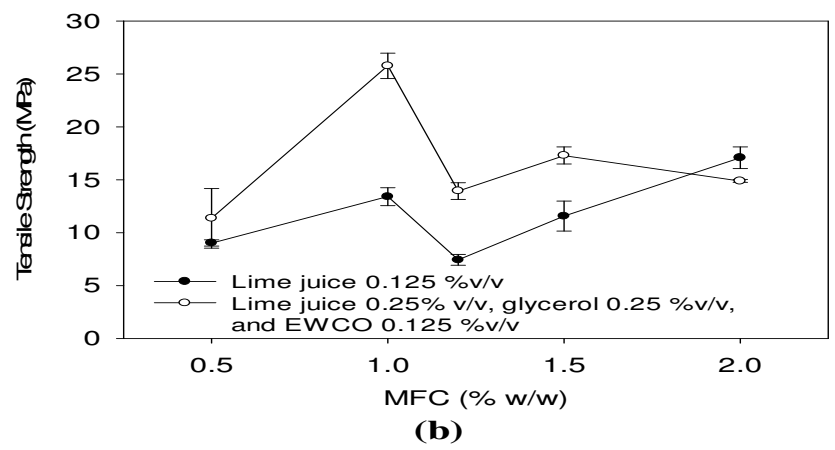

Fig.-1: (a) Effect of the EWCO in Blending Among the BS, Lime Juice, and Glycerol; (b) Effect of Plasticizer Addition of Biocomposite Preparation (Neat BS reinforced Neat MFC)

In the beginning, it was investigated the effect of bamboo MFC concentration (as reinforcement agent) at different plasticizer, i.e. glycerol and EWCO on bio-composite prepared by consisting of neat BS and neat MFC of bamboo, also lime juice as a crosslinker. The samples containing EWCO plasticizer have higher TS $(7.15-18.85 \mathrm{MPa})$ than the sample without EWCO $(3.31-9.91 \mathrm{MPa})$ at the same concentration of lime juice and glycerol. As shown in Fig.-1a, the blending of EWCO in composite led to increasing mechanical properties sharply up to $1.2 \%$-w/w of bamboo MFC, then sharply decrease when the content of MFC reaches $1.5 \%$-w/w indicating an increase in the stiffness of the composite. 
Further observation, plasticizers both of glycerol and EWCO made stiffer for the biocomposite than that of without plasticizers up to $2 \%$-w/w bamboo MFC content. Peak maxima of tensile strength were achieved at $25.8 \mathrm{MPa}$ with biocomposite plasticized both of glycerol $(0.25 \% \mathrm{v} / \mathrm{v})$, EWCO $(0.125 \% \mathrm{v} / \mathrm{v})$, cross-linked by citric acid of lime juice $(0.125 \%$-v/v), and reinforced by $1 \%$-w/w of MFC. It was visualized in Fig.-1b. This effect seems to be considered of the partial crosslinking among starch, citric acid of lime juice by the reaction between epoxide ring of the EWCO and hydroxyl group of starch and citric acid. The hypothesis of this reaction can be seen in Fig.-3. FTIR analysis was used to observe the reactive blending process of the EWCO in a mixture of neat and acetylated BS, neat and acetylated MFC, glycerol, and citric acid. Previous research observed in EWCO existed $720-730 \mathrm{~cm}^{-1}$ and $879 \mathrm{~cm}^{-1}$ denoted as single substituted epoxide and the vibrational of the ring in trans spatial of epoxide, respectively ${ }^{25,27}$. By blending in matric, it was apparently resulted acetyl group found in $1732 \mathrm{~cm}^{-118}$. In this research, spectra peak of EWCO disappeared along the epoxidize ring wavelength $\left(700-900 \mathrm{~cm}^{-1}\right)$. The FTIR spectra are reported in Fig.-2. It can be related opening reaction of EWCO by -COOH group (citric acid of lime juice) ${ }^{29}$. The plausible crosslinked structure of the incorporation of MFC within EWCO plasticized matrix formed by bagasse starch (BS). The plausible cross-linked structure is visualized in Fig.-3 (first reaction to the second reaction), while the schematic illustration of lime juice (citric acid), EWCO, glycerol, acetylated MFC, neat BS, and possible structure of crosslinked in Fig.-3 (third reaction) which adopted from other research ${ }^{30}$.

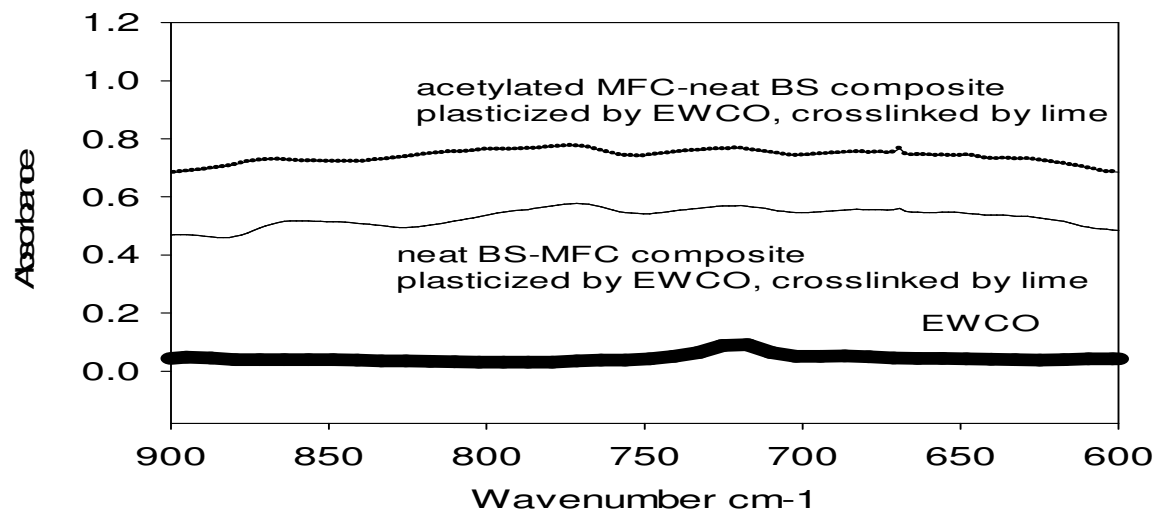

Fig.-2: The Spectra of FTIR for the Neat MFC-BS based Biocomposite and the EWCO

The neat BS has a more crystalline structure with narrow peak diffraction pattern (Fig.-4c and Fig.-4d). This trending also occurred for neat MFC and acetylated MFC. Fig.-4 presents no significant peak implying amorphous structure for acetylated BS. Decreasing formation of intermolecular hydrogen bonding on the structure is acquired from the esterification by replacing hydroxyl group on BS backbone, MFC backbone with an acetyl group ${ }^{31}$. Disruption of these narrow peaks is also attained by the plasticization process ${ }^{32}$. In this study, it was used MFC semi-crystalline with a peak of as shown in Fig.4a and Fig.-4b, while the used BS has an amorphous structure. Therefore, the neat and acetylated BS can easily disperse in the system.

It was utilized TGA analysis to observe thermal stability of biocomposite consisted of BS, MFC, lime juice, glycerol, and EWCO. Figure-5 represents thermal decomposition ( $\mathrm{T}_{\text {onset }}$ ) of the biocomposites increase more than $260^{\circ} \mathrm{C}$, while neat BS has lower $\mathrm{T}_{\text {onset }}$, of $258^{\circ} \mathrm{C}$. After acetylation, it was confirmed that due to the shifting of diffraction peak, it has higher thermal stability. It might result from the replacement of hydroxyl groups in BS, MFC, and citric acid of lime juice. Moreover, EWCO/glycerolplasticized MFC/BS-based composite was more thermally stable ${ }^{26}$. Commonly, the addition of plasticizers can decrease thermal stability due to the decrease of the vaporization of plasticizers ${ }^{33}$. The bio-plasticizer such as EWCO had higher degradation temperatures than that of the matrices. Accordingly, the decrease in thermal stability of biocomposite-plasticized did not result in the plasticizer 
vaporization. The observation obtained that biocomposite with neat MFC reinforced mixed of neat and acetylated BS plasticized by EWCO, glycerol, and crosslinked by citric acid from lime juice had a minimum of the weight loss during thermal analysis and the highest of degradation temperature, i.e. about $22 \%$ and $290{ }^{\circ} \mathrm{C}$, respectively. It was reported that the good plasticizer dispersion and their interaction with the matrices can increase degradation temperature by means the increase in thermal stability of the plasticized composite ${ }^{34}$. It is worth noting that the lowest onset temperature achieved at $263{ }^{\circ} \mathrm{C}$ considering higher as the allowed temperature of distribution and food processing ${ }^{33}$.

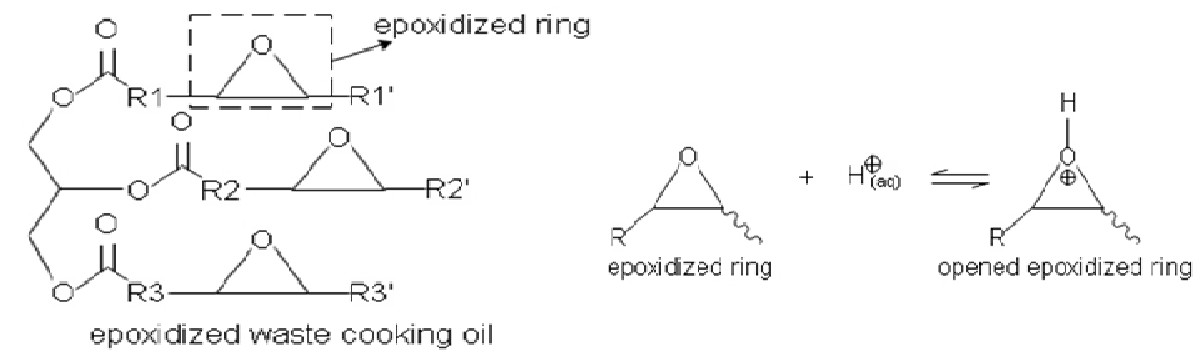

(1)

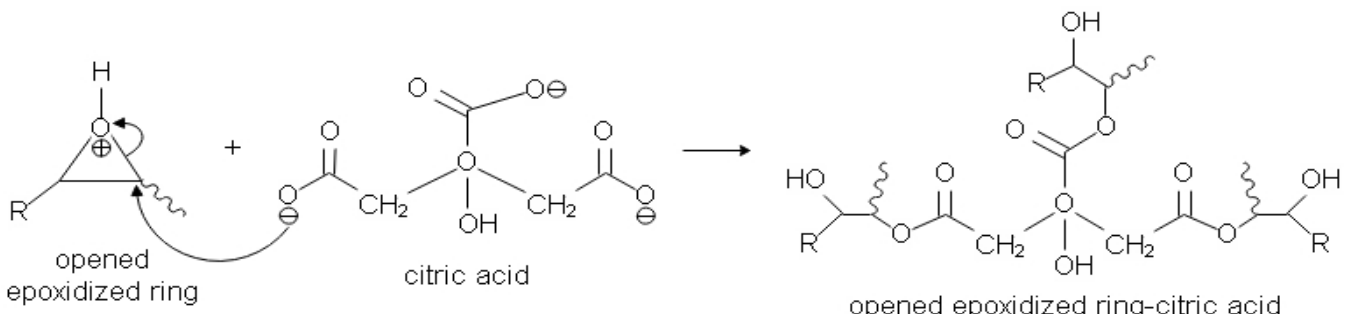

(2)

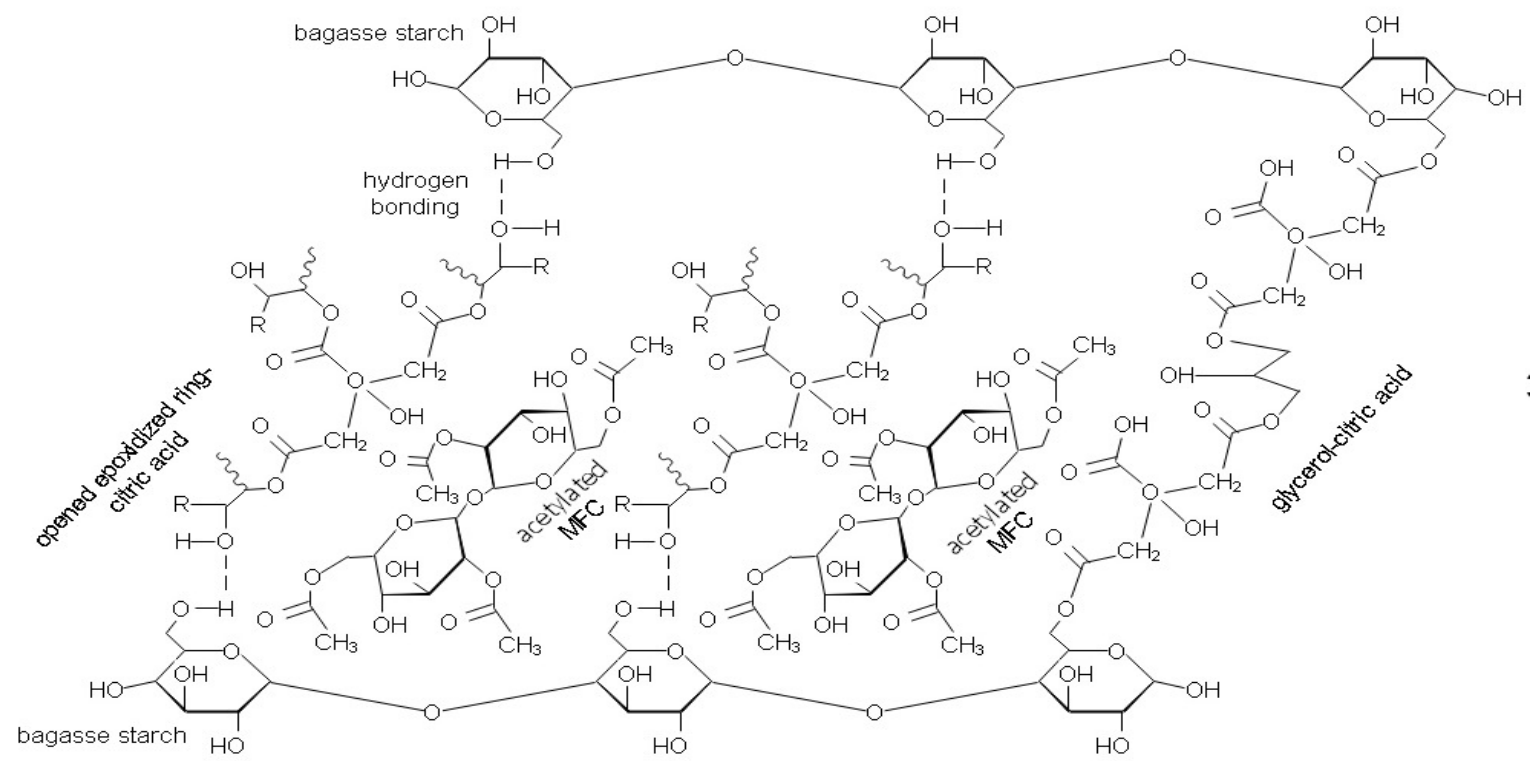

(3)

Fig.-3: Proposed Chemical Interaction (1) Opened Epoxidized Ring, (2) Opened Epoxidized Ring with Citric Acid, (3) BS, MFC, Citric Acid, Glycerol, and EWCO

The glass transition temperature is tabulated in Table-2. Glass transition is obtained as the onset temperature of DSC curve analysis. It can be seen, the acetylation of MFC and BS reduce $\mathrm{T}_{\mathrm{g}}$ and did not occur the peak maxima of crystallization regarding XRD analysis previously. However, in the present 
RASĀYAN J. Chem.

Vol. 12 | No. 3 |1470 - 1477| July - September | 2019

research, the decrease in biocomposite's $\mathrm{T}_{\mathrm{g}}$ from the addition of EWCO and lime juice were in variety range, with a maximum reduction of $33.53{ }^{\circ} \mathrm{C}$ (for acetylated MFC and neat BS), while mixture of acetylated MFC-BS and neat BS had an increase in $\mathrm{T}_{\mathrm{g}}\left(117.28^{\circ} \mathrm{C}\right)$. It was expected this biocomposite having no better miscibility between matrices of acetylated and neat BS with acetylated $\mathrm{MFC}^{26}$.

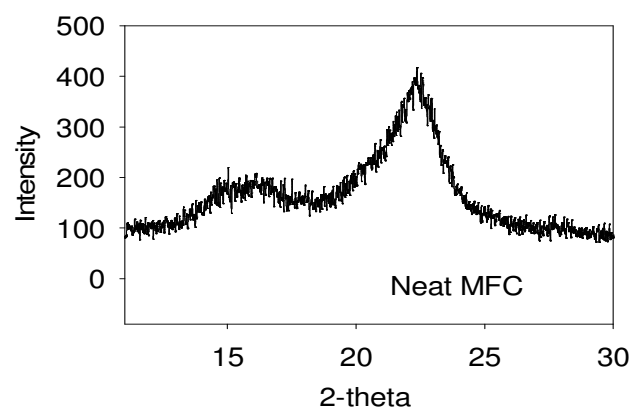

a)

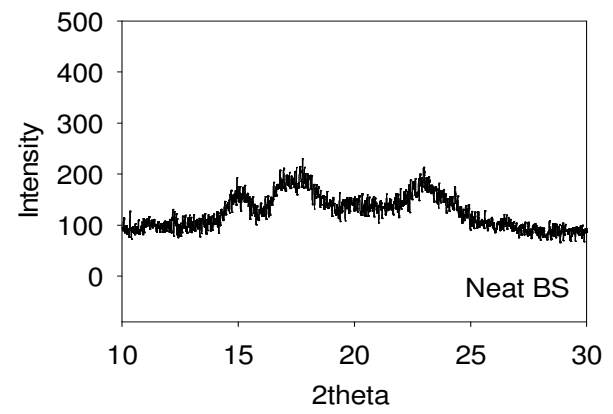

c)

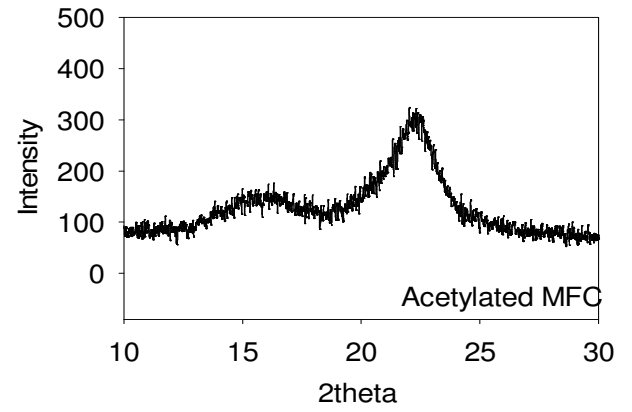

b)

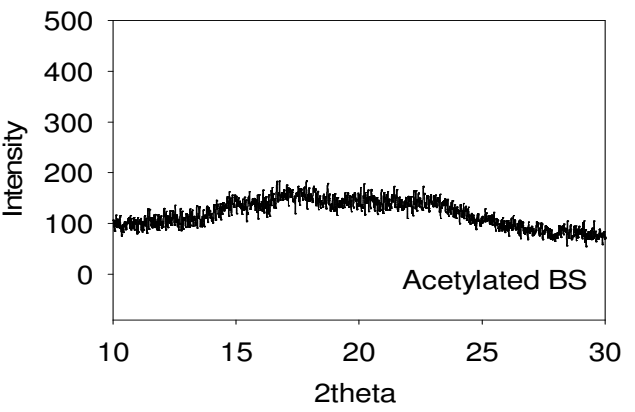

d)

Fig.-4: XRD Spectra of (a) the neat MFC (b) the acetylated MFC, (c) The neat BS (d) The acetylated BS

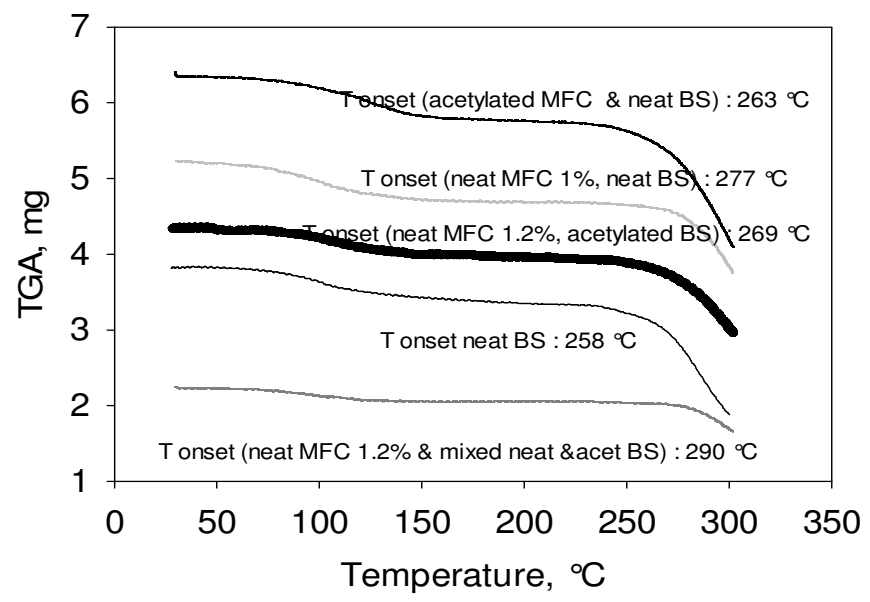

Fig.-5: TGA Curves of the Biocomposites at Various Kind of Components

Table-2: DSC Results for Various Biocomposites Plasticized with EWCO and Crosslinked with Citric Acid of the Lime

\begin{tabular}{c|c|c|c|c|c}
\hline Biocomposite & $\operatorname{Tg}\left({ }^{\circ} \mathrm{C}\right)$ & Biocomposite & $\operatorname{Tg}\left({ }^{\circ} \mathrm{C}\right)$ & Biocomposite & $\operatorname{Tg}\left({ }^{\circ} \mathrm{C}\right)$ \\
\hline Neat MFC & 81.14 & Neat BS & 86.30 & Neat MFC 1\%, neat BS & 65.66 \\
\hline Acetylated MFC & 65.23 & Acetylated BS & 82.15 & Neat MFC 1.2\%, neat BS & 77.89 \\
\hline & & Acetylated MFC, neat BS & 33.53 & Acetylated MFC & 117.28 \\
\hline
\end{tabular}


RASĀYAN J. Chem.

Vol. 12 | No. 3 |1470 - 1477| July - September | 2019

\section{CONCLUSION}

It was notably peak maxima of tensile strength in the biocomposite plasticized by EWCO and glycerol, crosslinked by lime juice, and reinforced MFC of $1 \%-\mathrm{w} / \mathrm{w}$. EWCO realized positive result to increase toughening the biocomposite from starch-based cassava bagasse. Therefore, bagasse starch derived from cassava solid waste and EWCO are the potential to introduce as matric and plasticizer, respectively. It was confirmed by product characterization including mechanical, thermal, and structure analysis. Moreover, sharply decrease the $\mathrm{T}_{\mathrm{g}}$ of the biocomposite with a mixture of acetylated MFC and neat BS was resulted from better miscibility between the mixture of matric and reinforcement. It is worth noting that the lowest onset temperature achieved at $263{ }^{\circ} \mathrm{C}$ considering higher as the allowed temperature of processing to achieve further purposes.

\section{ACKNOWLEDGMENT}

The authors are deeply grateful to the Research Board at Diponegoro University in Indonesia (101149/UN7.P4.3/PP/2018) for financial support of the research grant.

\section{REFERENCES}

1. G. Nandhavathy, S.P. Selvam, M.M. Kumar, E.R. Sadiku, Rasayan Journal Chemistry 10(2), 542(2017), DOI: 0.7324/RJC.2017.1021724

2. P.R. Salgado, S.E.M. Ortiz, S. Petruccelli, A.N. Mauri, Food Hydrocolloids, 24(5), 525(2010), DOI: 10.1016/j.foodhyd.2009.12.002

3. D.T. Blacido, P.J. Sobral, F.C. Menegalli, Journal of Food Engineering, 67(1-2), 215(2005), DOI: 10.1016/j.jfoodeng.2004.05.054

4. D. Liu, T. Zhong, P.R. Chang, K. Li, Q. Wu, Bioresources, 101(7), 2529(2010), DOI: 10.1016/j.biortech.2009.11.058

5. G.M. Souza, M.S.S. Junior, F. Yamashita, Materials Science and Engineering C, 33(6), 3153(2013), DOI: $10.1016 /$ j.msec.2013.03.042

6. J.F. Mendes, R.T. Paschaolin, V.B. Carmona, A.R. Seno-Neto, A.C.P. Marques, J.M. Marconcini, L.H.C. Mattoso, E.S. Medeiros, J.E. Oliveira, Carbohydrate Polymers, 137, 452(2016), DOI: 10.1016/j.carbpol.2015.10.093

7. E.D.M. Teixeira, A.A.S. Curvelo, A.C. Corrêa, J.M. Marconcini, G.M. Glenn, L.H.C. Mattoso, Industrial Crops and Products, 37(1), 61(2012), DOI: 10.1016/j.indcrop.2011.11.036

8. H. Ibrahim, M. Farag, H. Megaheda, S. Mehanny, Carbohydrate Polymers, 101, 11(2014), DOI: 10.1016/j.carbpol.2013.08.051

9. A.C. Souza, R. Benze, E.S. Ferrao, C. Ditchfield, A.C.V. Coelho, C.C. Tadini, LWT - Food Science and Technology, 46(1), 110(2012), DOI: 10.1016/j.lwt.2011.10.018

10. N. Van Cuong, T.Q. Hieu, P.T. Thien, L.D. Vu, L.V. Tan, Rasayan J. Chem. 10(4), 1446(2017), DOI: $10.7324 /$ RJC.2017.1041894

11. S. Acosta, A. Jimenez, M. Chafer, C. Gonzalez-Martinez, A. Chiralt, Food Hydrocolloid, 49, 135(2015), DOI: 10.1016/j.foodhyd.2015.03.015

12. M. Guimarães, V.R. Botaro, K.M. Novack, F.G. Teixeira, G.H.D. Tonoli, Industrial Crops and Products, 70, 72(2015), DOI: 10.1016/j.indcrop.2015.03.014

13. I.C. Guimarães, K.C. dos Reis, E.G.T. Menezes, A.C. Rodrigues, T.F. da Silva, I.R.N. de Olievera, E.V. de Baros Vilas Boas, Industrial Crops and Product, 89, 285(2016), DOI: 10.1016/j.indcrop.2016.05.04

14. S. Silviana, H. Hadiyanto, In AIP Conference Proceedings of the 3rd International Conference on Engineering, Technology, and Industrial Application, 030024-1(2017), DOI: 10.1063/1.4985494

15. H.D. Nguyen, T.T.T. Mai, N.B. Nguyen, T.D. Dang, M.L.P. Le, T.T. Dang, V.M. Tran, Advances in Natural Sciences: Nanoscience and Nanotechnology, IOP Publishing, 4, 015016-1(2013), DOI: 10.1088/2043-6262/4/1/015016

16. N. Lavoine, I. Desloges, A. Dufresne, J. Bras, Carbohydrate Polymers, 90(2), 735(2012), DOI: 10.1016/j.carbpol.2012.05.026 
RASĀYAN J. Chem.

Vol. 12 | No. 3 |1470 - 1477| July - September | 2019

17. A.S. Sánchez, Y.L. Silva, R.A. Kalid, E. Cohim, E.A.Torres, Renewable and Sustainable Energy Reviews, 73, 1265(2017), DOI: 10.1016/j.rser.2017.02.007

18. S. Silviana, S. Susanti, A. Subagio, In MATEC Web of Conferences of Regional Symposium on Chemical Engineering, 156, 01019-1(2018), DOI:10.1051/matecconf/201815601019

19. S.A. Bahari, A. Krause, Journal of Cleaner Production, 110, 16(2016), DOI: 10.1016/j.jclepro.2015.03.052

20. S.K. Ramamoorthy, M. Skrifvars, A. Persson, Polymer Reviews, 55, 107(2015), DOI: 10.1080/15583724.2014.971124

21. S. Silviana, L.A. Zuhri, M.M. Muzakki, A.K. Rahmawati, A.A. Marthasari, Advanced Science Letter, 23, 5739 (2017), DOI: 10.1166/as1.2017.8818

22. T.G. Dastidar, A. Netravali, ACS Sustainable Chemistry \& Engineering, 1(12), 1537(2013), DOI: $10.1021 / \mathrm{sc} 400113 \mathrm{a}$

23. T. Mekonnen, P. Mussone, H. Khalil, D. Bressler, Journal of Materials Chemistry A, 1, 13379(2013), DOI: $10.1039 / \mathrm{c} 3 \mathrm{ta} 12555 \mathrm{f}$

24. F.K. Siregar, D.Y. Nasution, Y. Muis, D.Y. Kaban, Rasayan Journal Chemistry, 12(2), 554(2019), DOI: $10.31788 /$ RJC.2019.1225126

25. S. Silviana, D.D. Anggoro, Advance Science Letters, 23(3), 2591(2017), DOI: 10.1166/asl.2017.8726

26. Y.B. Tee, R.A. Thalib, K. Abdan, N.L. Chin, R.K. Basha, K.F. Yunos, Bioresources, 11(1), 1518 (2016), DOI: $10.15376 /$ biores.11.1.1518-1540

27. S. Silviana, D.D. Anggoro, A.C. Kumoro, Chemical Engineering Transactions, 56, 1861 (2017), DOI: $10.3303 /$ CET1756311

28. S. Silviana, P.B. Brandon, B.A. Silawanda, Indonesian Journal of Chemistry, 18(4), 688(2018), DOI: 10.22146/ijc.26766

29. P. Gogoi, H. Horo, M. Khannam, S.K. Dolui, Industrial Crops and Product, 76, 346(2015), DOI: 10.1016/j.indcrop.2015.06.057

30. P.G. Seligra, C.M. Jaramillo, L. Fama, S. Goyanes, Carbohydrate Polymers, 138, 66(2016), DOI: 10.1016/j.carbpol.2015.11.041

31. A. Singh, L.K. Nath, M. Guha, Starch/Stärke, 63, 523(2011), DOI: 10.1002/star.201100012

32. M. Fazeli, M. Keley, E. Biazar, International Journal of Biological Macromolecules, 116, 272(2018), DOI: $10.1016 /$ j.ijbiomac.2018.04.186

33. M.P. Arrieta, M.M. Castro- López, E. Rayón, L.F. Barral-Losada, J.M. López-Vilariño, J. López, M.V. González-Rodríguez, Journal of Agricultural and Food Chemistry, 62, 10170(2014), DOI: 10.1021/jf5029812

34. N. Burdos, V.P. Martino, A. Jiménez, Polymer Degradation and Stability, 98, 651(2013), DOI: 10.1016/j.polymdegradstab.2012.11.009

[RJC-5240/2019] 